\title{
INTRODUCTION: ETHICAL ISSUES IN COVERT, SECURITY AND SURVEILLANCE RESEARCH
}

\author{
Ron Iphofen and Dónal O’Mathúna
}

\begin{abstract}
In light of the many crises and catastrophes faced in the modern world, policymakers frequently make claims to be 'following the science' or being 'governed by the data'. Yet, conflict based on inequalities continue to fuel dissatisfaction with the decisions and actions of authorities. Research into public security may require surveillance and covert observations, all of which are subject to major ethical challenges. Any neat distinction between covert and overt research is difficult to maintain given the variety of definitions used for all the terms addressed here. Covert research may be ethically justified and is not necessarily deceptive. In any case, deception may be ethical if engaged in for the 'right' reasons. Modern research sites and innovative research methods may enhance opportunities for covert work. In all surveillance and covert work, care must be taken about how consent is managed, how observed subjects are protected and harm to all involved minimised in all situations.
\end{abstract}

Keywords: Ethical surveillance; covert research; participant observation; security research; dual use; research ethics review

Ethical Issues in Covert, Security and Surveillance Research Advances in Research Ethics and Integrity, Volume 8, 1-8

Copyright $(\mathcal{2} 2022$ by Ron Iphofen and Dónal O’Mathúna. Published by Emerald Publishing Limited. These works are published under the Creative Commons Attribution (CC BY 4.0) licence. Anyone may reproduce, distribute, translate and create derivative works of these works (for both commercial and non-commercial purposes), subject to full attribution to the original publication and authors. The full terms of this licence may be seen at http://creativecommons.org/licences/by/4.0/legalcode ISSN: 2398-6018/doi:10.1108/S2398-601820210000008001 


\section{INTRODUCTION}

A series of major significant events and catastrophes have stimulated the developed world to better realise the widely different interpretations of what capitalist, liberal democracies see as progress: from 9/11, the Arab Spring, mass migrations from conflict-ridden regions of the world, to the COVID19 pandemic, various events have led to growing pressure to make sense of their causes and consequences. Policymakers look to 'science' to supply the answers, and claim they are 'following the science' when making decisions and policies. However, sometimes complex issues are thought through hastily, the studies used to inform policies are not carefully evaluated in terms of their methods or ethics, and policies are introduced with a degree of confidence not justified by the 'science.' When such policies turn out to be ineffective, the blame gets diverted to the researchers.

The scientific method and its application to the understanding of humanity and our environment has improved the human living condition significantly, but such improvements are not enjoyed by all. Inequality creates conflict which can lead to everything from distrust to despair, or in the face of overwhelming military dominance, can fuel radicalism and the continued development of terrorism by disaffected groups. Continuing research in the areas of defence, security and surveillance is critical to understand conflict, but carrying out such research raises distinct methodological and ethical challenges. Occasionally, the best research must be 'covert' or risk missing the key elements that account for events that are not willingly disclosed by those with malicious or nefarious intent, or by those who cannot risk becoming participants.

The notion of covert research has long held challenges for ethics reviewers. Part of the problem lies with precisely what is meant by 'covert'. If it simply refers to 'hidden' information relating to the research, then pretty much all research contains covert elements since only the active researcher, in the field or in the laboratory, knows everything that is going on and, in any case, it might not be in the interests of funders, co-researchers or research subjects to be told everything that is contained in or required of a research engagement. To do so might compromise the method and/or the research design without bringing any clear ethical advantage nor minimising any risks of harm to all involved (Iphofen, 2011).

Amongst some observers, another view exists that some inherently unethical research procedures exist, and covert observation is one of them. Such procedures can range from making observations of human behaviour in public places, or lurking on social media to observe how people manage their online relationships, to actively participating in a group or community without identifying oneself as a 'researcher'. This view of covert observation is seen by some as particularly problematic since it appears to necessarily imply deception since those being observed are not directly informed of the observation. Part of the problem here is with what one means by deception. We would argue that the term deception is used for a range of activities, not just telling a lie. It can involve an act or statement which misleads, or hides the 
truth, or promotes a belief, concept or an idea that is explicitly known not to be true (a lie). Deception can involve dissimulation, propaganda and sleight of hand, as well as distraction, camouflage or concealment, and deception can occur without being viewed as ethically problematic. For example, most commercial advertising is understood to be deceptive in the sense of manipulating the attractiveness of products and/or services in order to promote sales. We, the consumers, know that and vary in the ways in which we permit ourselves to be deceived by advertising. Yet, if the advertising stated that the product was available for $£ 100$, and nowhere sold it for less than $£ 1,000$, we would feel deceived in a way in which we would say was wrong because clearly false information was provided.

In a similar way, forms of 'deception' are vital to achieving research goals even whilst other forms are unethical. The research 'gold standard' of the double blind randomised controlled trial for drug therapies relies upon deliberate self-deception in terms of permitting the knowing concealment of the potentially 'active' substance and the application of a placebo. It is well known that part of the efficacy of a placebo for some subjects relies on the participants 'deceiving themselves' into believing they are, in fact, receiving the active substance. In other research, letting people know they are being observed might result in an alteration of their behaviour and prevent their 'true', or authentic natural behaviour, from being studied. Some research can involve a component of deception where, for example, participants are told they will be interviewed about a certain topic and audio visually recorded to help analyse the interview. This topic is part of the research study, but during every interview, a second researcher regularly gets phone messages and replies to them. Participants are not informed that the research had a second aim to analyse people's reactions to others responding to text messages during interviews. This is a form of deception, though the researchers do not explicitly lie to the participants.

If a research proposal is subject to ethics appraisal of some sort (a research ethics committee (REC) or institutional review board (IRB)) it may be the case that some members regard covert observation or deception as inherently unethical. If that were true, much of early social science would have been ruled out and many specific schools of thought (e.g. Chicago sociology and Stanford psychology) would have been proscribed. Even if no REC scrutiny is required of a research action, it remains the responsibility of the professional researcher to find the best way to protect their subjects, and themselves, when conducting research that has any degree of covert or deceptive elements within it.

Extensive opportunities for covert observation have emerged with the appearance of online social media which have given rise to new forms of community and personal identity for people which pose real challenges to the key ethical research principles of consenting, voluntary participation and vulnerability. At the same time, such media have given rise to innovative methodological approaches for researchers - in terms of access to a massive range of both qualitative and quantitative data and, as a result, our understanding of public and private space has become more complicated. 


\section{BEING COVERT}

Being covert in essence means that some, if not all, information is withheld about the fact that some research or 'evidence-gathering' activity is occurring. Taking such an approach requires ensuring an appropriate balance exists and has been justified between methodological requirements and the ethical responsibility to protect the subject from undue interference. If there are really strong methodological reasons for covert observation, and a study would be worthless without it, it could be justified - as long as there are no undue consequences for those under observation. Several of the chapters in this collection offer suggestions and examples about when this might be justifiable. Typically, this is done by concealing the identities of those being observed and the site of the study. The subject may be protected by ensuring that it would be impossible for anyone to find out who the subject of study is and where the study is being conducted. If such 'protection' and the 'value' of the study (to society and, possibly, even to the individuals/group under study) outweighs any conceivable harm - the ethical justification is strengthened. But neither full protection nor full lack of intrusion can be guaranteed and the notion of what constitutes 'harm' can vary greatly between individuals. These justifications are complex, and people will differ in their overall assessments of the arguments.

For both covert and any form of surveillance research a conventional solution is to somehow signal to those who might be affected that the work is being carried out - such as notices in public venues or social media sites, or, for studies in workplaces, notices sent to all staff likely to be present. Inevitably, this compromises the research design to some degree: the subjects might behave differently as a consequence of knowing that they might be observed; the sample selection might be compromised as all the subjects might not have seen the research notices and may behave differently; the reliability of the evidence gathered might thus be interfered with; and, more problematically, this approach might not even secure valid informed consent. There would be no evidence, other than the notice, that the population/subjects were truly informed. People could say they had not seen the notice and, if they hear about it subsequently, could get upset about being observed. There would then have to be a grievance procedure for redress of any perceived harm - once again compromising the methodology.

One thing that is agreed upon is the need to secure the consent of the owners of the premises, site and/or organisation in which the study is to occur. Insurance indemnity issues will be involved for sure. This has become a particular bone of contention in social media studies where it is argued that 'the expectation of privacy' is illusory and by no means protected by any statements of terms and conditions (see Woodfield, 2018). Some suggest that there should be little concern about observations in public places for a range of reasons: people are observing each other anyway; we sit in café terraces and 'watch the world go by', and people do not complain. Whether we make notes about what we see, or write about and publish our observations, is of secondary concern. If people are unhappy about how they are described, and their identities revealed, the only thing they can do is to take it to law. Journalists and novelists are less bothered about this sort of behaviour than professional researchers. One could argue that the researcher's motives are likely to be more 'pure' - whatever that means! 


\section{RESTRICTING INFORMED CONSENT}

Situations occur when information about the full nature of a study may have to be restricted in order to comply with a specific research design. This is particularly likely to occur with covert participant observational studies or ethnographic field research in which the researcher's role is not fully disclosed - also known as immersive fieldwork. To seek consent from 'subjects' or site owners in such a situation would nullify the research method and the rationale for its adoption. But any exemptions to seeking consent must be detailed together with an explanation of why they have occurred. Thus, there may be broad methodological justifications and more specific, strategic reasons to do with the safety of researchers and/or research subjects quite apart from securing the research design. Incomplete disclosure may be justified if it entailed minimal risks to the subjects, if some way of debriefing them could be made available, and, perhaps, if there were a way to provide for the appropriate dissemination of findings to subjects. In fact, it may be the case that subjects could suffer from information overload' if they are told too much. After all they are not the professionals whose careers are dependent upon satisfactory outcomes. Even some form of retrospective consent could be sought to allay fears.

Observational studies in which the participants are not and never will be made aware that they are being observed offer the best examples of exceptions to fully informed consent. There have been many such 'classic' ethnographic studies in the history of social science research and they usually cover the fringe areas of society criminality, social deviance, the sex industry, terrorist groups and religious cults. In a classic text, Moser and Kalton (1971) described observation as '... the classic method of scientific enquiry' (p. 244) and expressed surprise at the relatively infrequent use of observational methods by social scientists when one reflects that '.. they are literally surrounded by their subject matter'. Their only ethical concern was that:

The method must be suitable for investigating the problem in which the social scientist is interested; it must be appropriate to the populations and samples he [sic.] wishes to study; and it should be reasonably reliable and objective. (Moser \& Kalton, 1971, p. 244)

They do caution about the potential for bias since it depends upon the observer's recording skills and their interpretations of the meanings or intentions behind the behaviour:

\footnotetext{
[...] observers are so much part of their subject matter that they may fail to see it objectively;

... their vision may be distorted by what they are used to seeing or what they expect to see; and

... they may find it hard to present a report in which observation is satisfactorily distinguished

from inference and interpretation. (Moser \& Kalton, 1971, p. 253)
}

\section{COVERT STUDIES}

Sidhir Venkatesh claims that he could not have conducted his research on hustlers, prostitutes and drug dealers in any detail if they had been aware of his status as a researcher. His analysis of a drug dealing gang's accounts demonstrated how it adopted a business model successfully employed by many other modern 
businesses. He explains that conventional research instruments such as questionnaires and interview schedules would be entirely inappropriate and ineffective in such situations and would not help researchers trying to learn about the lives of poor and marginalised communities. He saw that just as his research subjects were 'hustling' for money, drugs, sexual favours and so on, he was also hustling for the data that he saw as vital to his research goals. He had to become imaginative, devious and, therefore, covert in gaining information - otherwise he would be seen as an agent of the authorities and a threat to his respondents' access to services (Venkatesh, 2008).

It is vital that during the ethics appraisal process - via RECs or IRBs - the use of deception that is necessarily an element of covert research and/or surveillance should not be necessarily ruled out as inherently morally unacceptable. The question facing an ethics committee should not be: 'Is deception wrong?' To answer that in the affirmative would be to deny practices that are central to human civilisation - politics, economics and, indeed, normal social interaction. Rather the committee should ask: 'Would the form of deception proposed or implied here harm the research participants, the researchers and/or society in general in any way?' This is not an easy question to answer since the harms would have to be balanced against the benefits accruing to all of those constituent groups if the research was conducted successfully. As Robert Rosenhal has pointed out:

[...] the ... researcher whose study might reduce violence or racism or sexism, but who refuses to do the study because it involves deception, has not solved an ethical problem but only traded it in for another. (cited in Bok, 1979, p. 192)

Another key question about deception has to do with whether or not it damages the trust the general public (and so future potential research participants) have in researchers. If deception leads to an undermining of trust, and so a reluctance to participate in research, this is a risk to the success of future research projects (Bok, 1979, p. 205 et seq.). The benefits to society of future research are thereby jeopardised by the 'contamination of the field'.

\footnotetext{
Thus, we are always confronted with a conflict of values. If we regard the acquisition of knowledge about human behaviour as a positive value, and if an experiment using deception constitutes a significant contribution to such knowledge which could not be very well achieved by other means, then we cannot unequivocally rule out this experiment. The question for us is not simply whether it does or does not use deception, but whether the amount and types of deception are justified by the significance of the study and the unavailability of alternative (that is, deception-free) procedures. (Kelman, 1967 in Bynner \& Stribley, 1979, p. 190)
}

Another way of addressing this is to consider it alongside the issues of consent and vulnerability. Thus, if the form of deception proposed in a research project minimises the research subjects' capacity to consent and makes them more vulnerable to harm without substantially contributing to societal benefit then it becomes harder to ethically justify it going ahead. It is a complex question - but one that cannot be dealt with simply by suggesting that deception in research is inherently wrong. 


\section{INTRUSIVENESS}

Finally, ethics review committees often ask whether a piece of research is likely to be excessively intrusive and so 'disturbing' the subjects' normal life routines. Of course, all research is to some extent intrusive, but that intrusiveness is variable - dependent upon how much of the respondents' time, energy and so on it takes up and, not to be forgotten, how intrusive the subsequent reporting of findings might be. Intrusiveness also needs to be balanced against the concerns addressed above - thus, ironically, the more covert a piece of research, the less intrusive in ordinary lives it is likely to be. It might become more intrusive depending upon how and where research findings are published - but that merely raises another set of ethical concerns.

In practical terms, then, to maintain the dignity and personhood of research subjects one would have to anticipate the potential limitations to their participation in research and adjust methodologies accordingly. So, perhaps paradoxically, given the condemnation of covert research in some circles, it could be argued that observation could be the least intrusive way of researching aspects of the lives of vulnerable people since it is less likely to challenge them emotionally and physically. A range of naturalistic observation methods could be employed for which in some cases they need not be made aware and, in others, might be positively enjoyed (Clark, 2007). In qualitative research, in particular it may be impossible to maintain a neat distinction between covert and overt research. Again, as Murphy and Dingwall (2001, chapter 23) have explained, settings are often more complex and changeable than can be anticipated.

\section{THIS VOLUME}

Drawing on an international authorship, this volume strives to address these key and often overlapping issues that become entangled in so many contemporary research ethics challenges. The volume begins with a general overview of the ethical issues with surveillance research, before considering the benefits and challenges of handling Big Data and how this affects concepts of privacy. This is seen as important to provide security in an increasingly insecure society, especially in relation to state intervention and monitoring, but such research must be conducted responsibly to avoid fuelling further distrust. The theme of privacy in civil society is considered in Chapter 3 in relation to the issues facing researchers seeking consent to conduct research using surveillance or covert or deceptive methods. Chapter 4 explores covert research in greater depth, exploring reasons for and against the use of various forms of covert methods. Chapter 5 examines a trend within research to explore correlation rather than causation, which raises a number of ethical issues, particularly in the context of Big Data, the focus of a number of subsequent chapters. Chapter 6 examines claims that ethical issues with Big Data are addressed through anonymisation, and points to the need for an ethical framework to ensure data are collected and used appropriately. Chapter 7 switches focus to examine ethical concerns with state authorities using healthrelated data for non-health purposes, and the implications of this for researchers 
using such data. Chapter 8 turns to examine data protection in a German context given its distinct historical experience with state authorities surveilling citizens for the purposes of oppression. The ethical issues with dual use research are examined in Chapter 9, especially when research results have the potential to be used for military purposes. Chapter 10 explores ethical tensions between community-based and systems-based (or organisational) approaches to address security concerns amongst humanitarian workers. Chapter 11 continues the focus on security research and examines the challenges of collecting data using various research methods in ways that protect participants from security breaches. The final chapter provides two concise lists of recommendations for research involving surveillance, covert and deceptive methods. One set of guidance is provided for reviewers of such research, and another set for policymakers. We offer these as a concise summary of the in-depth discussions and analyses provided throughout the volume by this group of internationally esteemed and respected authors.

\section{REFERENCES}

Bok, S. (1979). Lying: Moral choice in public and private life. New York, NY: Vintage Books.

Clark, A. (2007). Making observations: The potential of observation methods for gerontology. London: Centre for Policy on Ageing.

Iphofen, R. (2011). Ethical decision making in social research: A practical guide (pp.8, 36, 41, 45-46, 79 et seq). London: Palgrave Macmillan.

Iphofen, R. (2011/2013). Research ethics in ethnographylanthropology (DG Research and Innovation). Brussels: European Commission.

Kelman, H. C. (1967). Human use of human subjects: The problem of deception in social psychological experiments. Psychological Bulletin, 67, 1-11. Republished in Bynner, J., \& Stribley, K. M. (1979). Social research: Principles and procedures. London: Longman.

Moser, C. A., \& Kalton, G. (1971). Survey methods in social investigation (2nd ed.). Aldershot: Ashgate (2001 reprint) (first published 1958).

Murphy, E., \& Dingwall, R. (2001). The ethics of ethnography. In P. Atkinson, A. Coffey, S. Delamont, J. Lofland, \& L. Lofland (Eds.), Handbook of ethnography (pp. 339-351). London: Sage.

Venkatesh, S. (2008). Gang leader for a day. London: Allen Lane.

Woodfield, K. (2018). The ethics of online research (Advances in Research Ethics and Integrity, Vol. 2). Bingley: Emerald Publishing Limited. 